\title{
EMPIRICAL STUDY OF MEASURING SUPPLY CHAIN PERFORMANCE
}

\author{
Dr. Ilkka Sillanpää, University of Vaasa, Finland \\ ilkka.sillanpaa@student.uwasa.fi
}

\begin{abstract}
Purporse Supply chain performance measurement - the process of qualifying the efficiency and effectiveness of the supply chain. The aim of this study is to create a supply chain measurement framework for manufacturing industry, define which data should be measured and verify the measurement framework in the case company's supply chain.

Design/Methodology/Approach There is a review of the current understanding of supply chain management and literature related to supply chain performance measurement and the study creates a framework for supply chain measurement. This research is qualitative case study research.
\end{abstract}

Findings This study presents the main theoretical framework of supply chain performance measurement. The key elements for the measurement framework were defined as time, profitability, order book analysis and managerial analysis. The measurement framework is tested by measuring case supply chain performance.

Limitations In the study, a performance measurement framework was created for the needs of manufacturing industry.

Practical implications The measurement framework in this study offers guidelines for measuring the supply chain in manufacturing industry but the measurement framework could be used in different areas of industry as well.

Originality/Value The measurement framework is a valid framework for supply chain performance measurement in manufacturing industry.

Keywords: supply chain performance measurement, supply chain management, manufacturing industry 


\section{INTRODUCTION}

In particular, measuring the supply chain (SC) has been recognized as a problem. The problem occurs when developing a SC in practice. The pressures in rationalizing set by management create a significantly large challenge for supply chain management (SCM). The SC has to be made more streamlined, lead-times have to be decreased, excess processes need to be eliminated and developed as a whole in such a manner that new, more efficient processes can be established. The basis for development work is a survey of the present state and measuring efficacy of the current SC. Tools for this have been scarce. This study provides a resolution to problems in measuring the SC.

Typically SC performance measurement research has been carried out via questionnaires and they have not had an action oriented point. Measuring the SC is the basis for developing it. It is possible to evaluate the SC when it can be measured. Likewise, it is possible to evaluate efficiency by following indicators of SC. The research goal can be captured as following:

The goal is to deepen knowledge in supply chain performance measurement in manufacturing industry.

The research problem is presented as a question:

How to measure supply chain performance in manufacturing industry?

\section{SUPPLY CHAIN PERFORMANCE MEASUREMENT}

This chapter presents primary approaches for SC performance measurement. First, the emergence of SCM concept is reviewed. After this, SCM is defined according to the views of various academics. It is possible to measure SC performance in several ways and performance measurement in the SC context has been studied in many perspectives.

\section{Supply chain management}

Supply chain management (SCM) is a management concept of the 2000's. It includes divisions from the management concepts of previous decades. Many definitions for SCM have been presented. SCM has been and is still regarded as a synonym for logistics, supply and SC control. Today the broader definition determined by the Global Supply Chain Forum is generally accepted as a norm (Lambert, Cooper and Pagh 1998; Cooper, Lambert and Pagh 1997):

"Supply Chain Management (SCM) is the integration of key business processes from end user through original suppliers that provides products, services, and information that add value for customers and other stakeholders" 
Christopher uses the terms "supply network" or "supply web" to describe the net-structure of most of the SC's. He emphasizes the network-nature of his SC definition (Christopher 1998): "Supply chain is a network of organizations that are involved, through upstream and downstream linkages, in the different processes and activities that produce value in the form of products and services in the hands of the ultimate customer".

Aitken (2005) defines SCM as following (Aitken et al. 2005):

The supply chain is defined as the network of connected and interdependent organizations that work together to enable the flow of products into markets, whereas a "pipeline" is defined as the specific operational mechanisms and procedures that are employed to service specific product/market contexts.

SCM emphasises both the overall and long-term benefit for all parties in the SC through cooperation and information sharing. Simchi-Levi et al. (2004) define SCM as (Simchi-Levi, Kaminsky and Simchi-Levi 2004):

A set of approaches used to efficiently integrate suppliers, manufacturers, warehouses and stores so that merchandise is produced and distributed at the right quantities, to the right locations, and at the right time in order to minimize system-wide costs while satisfying service-level requirements.

SCM is generally considered to involve integration, coordination and collaboration across organisations and throughout the supply chain (Stank, Keller and Daugherty 2001).

Nayron (1999) defines supply chain as following (Ben Naylor, Naim and Berry 1999):

A supply chain is a system whose constituent parts include material suppliers, production facilities, distribution services and customers linked together via a feed forward flow of materials and feedback flow of information.

Supply Chain Operations Reference model (SCOR) which was defined in the Supply Chain Council (2005), defined a SC as follows (Supply Chain Council 2005):

"The supply chain encompasses every effort involved in producing and delivering a final product, from the supplier's supplier to the customer's customer. Five basic processes-plan, source, make, deliver and return - broadly define these efforts, which include managing supply and demand, sourcing raw materials and parts, manufacturing and assembly, warehousing and inventory tracking, order entry and order management, distribution across all channels, and delivery to the customer." 


\section{Performance measurement in supply chain context}

"When you can measure what you are speaking about, and express it in numbers, you know something about it..." Lord Kelvin, 1824-1907

"You cannot manage what you cannot measure", (Sink, Tuttle 1989)

There is a set of contributions in the area of SC performance measurement. Chan and Qi (2003) proposed a process-based PMS for mapping and analyzing complex SC networks (Chan 2003a); van Hoek (2001) emphasizes the importance of performance measurement from the point of view of the third-party logistics alliances in SC (Van Hoek 2001); Gunasekaran et al. (2001) develop performance measures and metrics in a SC environment from a managerial point of view (Gunasekaran, Patel and Tirtiroglu 2001). Morgan (2004) offers nine preconditions necessary for effective and dynamic performance measurement within SC's. These preconditions are cheap and reliable identification of units in transition, standard protocols, communication systems that are capable of handling the volume of data, hardware and software, multi-layered control systems, system handshake protocols, routing and re-routing protocols that allow SC cost control, speed and flexibility of delivery response, high velocity electronic cash transfers instigated automatically; and robust systems with inbuilt automatic recovery abilities (Morgan 2004). Thakkar et al. (2007) proposed a balanced scorecard (BSC) framework for a case organization using an integrated approach of interpretive structural modelling and analytic network process (Thakkar et al. 2007).

According to the research, SC capability can be measured by using different kinds of approaches:

- A Performance measurement matrix (Keegan, Eiler and Jones 1989)

- Financial and/or non-financial metrics (Gosselin 2005; Ittner et al. 2003; Kaplan and Norton 1992; Lambert and Pohlen 2001; Lawrie and Cobbold 2004; Neely 1999; Olsen et al. 2007; Tangen 2004; Tapinos et al. 2005; Thakkar et al. 2007)

- Qualitative or quantitative approach (Beamon 1999; Chan 2003a)

- Balanced scorecard approaches (Bigliardi and Bottani 2010; Chia, Goh and Hum 2009; Dror 2008; Xu and Li 2008; Bhagwat and Sharma 2007; Thakkar et al. 2007; Lawrie and Cobbold 2004; Brewer and Speh 2001; Kaplan and Norton 2001; Brewer and Speh 2000; Epstein and Manzoni 1998; Kaplan and Norton 1996; Kaplan 1996; Kaplan 1993; Kaplan and Norton 1992)

- Performance prism (Neely et al. 2000)

- Performance measurement questionnaire (Dixon 1990)

- Van Hoek’s matrix model (Hoek 1998) 
- Cost and non-cost (Gunasekaran et al. 2001; Toni and Tonchia 2001)

- Quality, cost, delivery and flexibility (Shepherd and Gunter 2006)

- Cost, quality, resource utilization, flexibility, visibility, trust and innovativeness ()

- Resources, outputs and flexibility (Beamon 1999)

- SC collaboration efficiency; coordination efficiency and configuration (Shepherd and Gunter 2006)

- Input, output and composite measures (Chan 2003a)

- Strategic, operational or tactical management approach (Gunasekaran, Patel and Tirtiroglu 2001)

- SC process based measuring approach (e.g. Shepherd and Gunter 2006; Chan 2003a)

- Six-sigma approaches (Lin and Li 2010; Ramaa, Rangaswamy and Subramanya 2009; Xu 2008; Wang, Du and Li 2004; Dasgupta 2003)

- Measuring SC in multiple levels (Shepherd and Gunter 2006; Lin and Li 2010)

\section{Table 1: Performance measurement approaches}

\begin{tabular}{llc}
\hline Author & Framework / Performance measures / Performance & Category \\
& Measurement System (Quality (Q) Cost (C) Delivery(D) & of Measure \\
& Flexibility (F) Agility (A) Responsiveness(R) Non-financial & \\
& (NF) Qualitative (QL) Quantitative (QN) )
\end{tabular}

\begin{tabular}{lll}
\hline Beamon (1999) & Resources, output and flexibility & QN \\
Holmberg (2000) & Performance model with system perspective, cost, speed and & C, A, Q \\
& customer service level, agility & \\
Suwignjo, Bititci & Quantitative model & QN
\end{tabular}

and Came (2000)

Gunasekaran, Patel Strategic, operational and tactical focus $\quad$ QN, QL and Tittiroglu (2001)
Stephens (2001)
Measures based on process
$\mathrm{C}, \mathrm{R}, \mathrm{QN}$
De Toni and
Cost and non cost
$\mathrm{C}, \mathrm{NF}$

Tonchia (2001)
Hieber (2002) Supply chain collaboration efficiency; coordination efficiency Q, QN and configuration
Chan (2003) Cost, quality, resource utilization, flexibility, visibility, trust
$\mathrm{C}, \mathrm{Q}, \mathrm{QN}$,


Chan and Qi Input, output and composite measures, processes of supply $\quad$ QN, QL chain

Chunhua Tian, Quality, cost, delivery and flexibility perspective performance C, Q, QN, Yeuting Chai, Yi measures at department, enterprise and supply chain level F, A Liu, Shouju Ren

Felix T S Chan et Innovative Performance Measurement Method

Q, QN,

al. (2003)

Stefan Tangen, Financial, time based measures, non cost

QL (2003)

Changrui Ren, Active performance management system QN, QL

Yueting Chai, Yi

Liu (2004)

Archie Lockamy

SCOR model

QN

III, Kevin

McCormack

David J. Parsons, Relationship between productions run lengths and overall

QN, Q

Robin J. Clark, supply chain performance

Kevin L. Payette,

(2004)

Quality, cost, delivery and flexibility

$\mathrm{Q}, \mathrm{C}, \mathrm{D}, \mathrm{F}$

Schonsleben(2004)

Gunasekaran et al. Framework for measuring costs and performance

$\mathrm{C}, \mathrm{NF}$ (2005)

Li, S., Rao, et al. Strategic supplier partnership, CRM, information sharing, QL,QN, (2005) quality, internal lean practices and postponement

Q, C

Liwen Wu, Yutao

Finance, business processes, customer, environment, core

C, QN

Song (2005) enterprise ability

Fynes, B., Voss, Quality, framework incorporating dimensions of SC

Q, QN

C., Búrca, S. D. relationships and quality performance (2005) 


\begin{tabular}{|c|c|c|}
\hline Abhijeet K. & Theoretical framework for the performance measures of & $\mathrm{QN}, \mathrm{Q}, \mathrm{C}$ \\
\hline Digalwar, & World Class Manufacturing & \\
\hline \multicolumn{3}{|l|}{ Bhimaraya A. } \\
\hline \multicolumn{3}{|l|}{ Metri (2005) } \\
\hline MAO Zhaofang et & Supporting evaluation level(HITS-Human, Institution, & $\mathrm{QL}, \mathrm{T}, \mathrm{Q}$, \\
\hline al. (2006) & Technology, Surroundings) and operational evaluation & $\mathrm{C}$ \\
\hline & level(TQFS -Time, quality, Finance and service) & \\
\hline Z., Li, X. Xu, and & Supply chain performance measurement approach which & $\mathrm{QN}, \mathrm{C}, \mathrm{Q}$ \\
\hline \multicolumn{3}{|c|}{ Arun kumar (2007) evaluate } \\
\hline & levels & \\
\hline \multirow[t]{2}{*}{ Tong Ren (2008) } & Supply Chain Performance Measurement Based on SCOR & QN \\
\hline & Model & \\
\hline
\end{tabular}

Source: Beamon 1999; Chan 2003a; Gunasekaran, Patel and Tirtiroglu 2001; Ramaa, Rangaswamy and Subramanya 2009; Holmberg 2000; Suwignjo, Bititci and Carrie 2000; Stephens 2001; De Toni, Tonchia 2001; Hieber 2002; Chan 2003b; Chan and Qi 2003a; Tangen 2004; Lockamy III; McCormack 2004; Gunasekaran, Williams and McGaughey 2005; Li et al. 2005; Fynes, Voss and De Búrca 2005, Li, Xu and Kumar 2007; Ren 2008; Chan and Qi 2003b.

\section{Supply chain performance measurement in the case company}

As it emerged from the theoretical study, managing the $\mathrm{SC}$ has to be measured at various different levels using various approaches. For measuring SC, the barometers have to be tailored case-specifically for each SC.

The SC of the case company can be measured with the following indicators, taking into consideration the special characteristics of the SC: order book analysis, profitability, time, managerial analysis. 


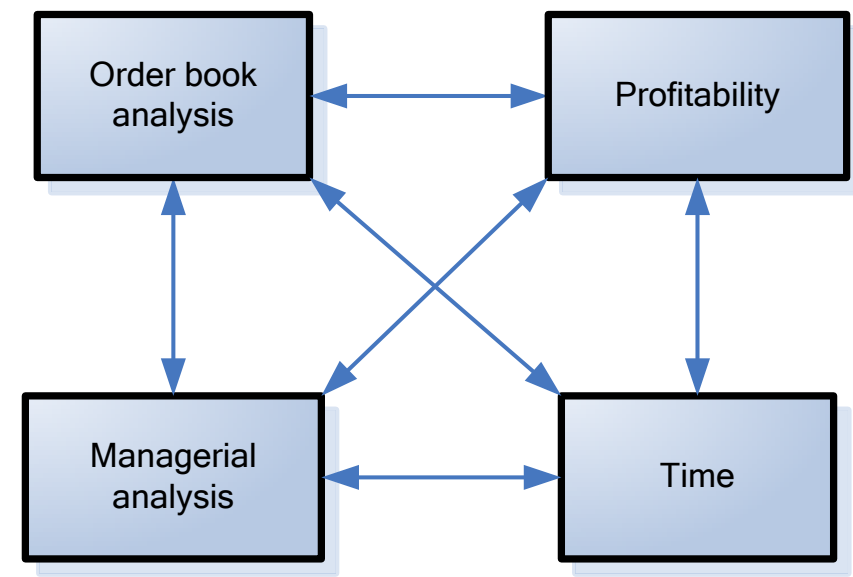

Figure 1: Supply chain performance measurement indicators

\section{Order book analysis}

Measuring the SC of a production plant has its foundation in order book analysis. According to the survey to literature, order book analysis can be categorized to non-financial metrics (Gosselin 2005; Kaplan and Norton 1992; Lambert and Pohlen 2001; Lawrie and Cobbold 2004; Neely 1999; Olsen et al. 2007; Tangen 2004; Tapinos et al. 2005; Thakkar et al. 2007), qualitative approach (Beamon 1999; Chan 2003a), and non-cost (Gunasekaran et al. 2001; Toni and Tonchia 2001). The aim is to gain information regarding the present state of the order book of the production plant. Percentage of delivery to customers of total sales as well as percentage of various deliveries for internal sales from total sales can be regarded as the most central indicators.

Weekly manufacturing amounts suggest the average load of production. With the help of manufacturing figures it is possible to verify seasonal variation and possibly the effect of manufacturing amounts to on-time delivery. Delivery amounts should be reviewed as tons. One should analyze weekly and monthly variation of delivery amounts to internal and external customers. Amounts produced are, from the point of view of running the production plant, an essential measurable quantity. In the light of previous amounts produced - together with the sales forecast obtained from sales - it is possible to plan future capacity and future production.

\section{Profitability}

It is important for a company manufacturing prefinished products in an engineering works to measure efficacy of the SC from the point of view of cost-efficiency. The profit directed at the order describes cost-efficiency best. On the basis of theoretical review, this indicator is 
numbered among cost and economic viewpoint indicators (Gosselin 2005; Gunasekaran et al. 2001; Kaplan and Norton 1992; Lambert and Pohlen 2001; Lawrie and Cobbold 2004; Neely 1999; Olsen et al. 2007; Tangen 2004; Tapinos et al. 2005; Thakkar et al. 2007; Toni and Tonchia 2001). The indicator can be generalized as a fundamental indicator for all production companies. The indicator is especially important by the fact that the price of steel varies according to markets and therefore updating the prices for products and continuous follow-up on sale prices for these to meet the actual expenses is extremely important. In the steel service business the sales usually occur on the basis of spot transactions, but additionally the company operating in the field of pre-fabricated plate product business has committed to deliver products to its customers according to long-term contracts. Therefore, re-counting of the products according to changes in production schedules is extremely important.

\section{Time}

Lead-time is in many studies considered to be one of the central indicators in manufacturing industry. De Toni et al. present time-based indicators as non-cost indicators, where time can be measured as internal or external time (Toni and Tonchia 2001). Gunasekaran et al. (2004) present a great deal of time-based measures (Gunasekaran, Patel and McGaughey 2004) Time is also identified as the next source of competitive advantage (Kessler and Chakrabarti 1996; Vesey 1992; Stalk 1988; Balsmeier and Voisin 1996; Mehrjerdi 2009). Also in measuring the SC several scholars recognize lead-time to be a very descriptive indicator. In the case company, lead-time is one of the most important elements that the customer is interested in. Quick times of delivery in the steel service business make the business hectic and therefore lead-time has to be measured in order to be able to decrease it.

\section{Managerial analysis}

In measuring the SC one has to review the SC as a whole. Partial optimization has to be avoided because improving one sector is not enough to improve the whole SC. Gunasekaran et al. state that several kinds of measures should be used in performance metrics: balanced approach, strategic, tactical and operational levels and financial and non-financial measures. SCM could be measured at a different management or operation level. (Gunasekaran et al. 2001; Gunasekaran et al. 2004). It is useful to gather managerial analysis from analyses of people involved in the SC as well as analyses of outsiders.

Managerial analysis can be performed on the basis of measured information obtained from the systems, making visual perceptions in production and interviewing professionals involved in 
the production process. The purpose of managerial analysis is to follow-up the whole SC and obtains information regarding immeasurable issues related to SC. The purpose of observation is also to obtain information regarding efficacy of the SC so that evaluation will not be based merely on measured quantities.

\section{EMPIRICAL SUPPLY CHAIN PERFORMANCE MEASUREMENTS}

In this chapter the SC is measured with previously established indicators. The indicators consist of four different parts: order book analysis, profitability, time and managerial analysis. In order book analysis, the production plant's completed output and reliability of delivery in different years are reviewed. SC can be also measured from the point of view of profitability. Also the costs of the SC are observed. Time-based measuring of the SC is conducted by measuring the delivery cycle, delivery accuracy, production time and its subdivision into operational times. It is extremely important to make managerial analyzes where analyses are made on operational, tactical and strategic levels.

\section{Case description}

The case company is a steel service center which serve as steel refiners. Steel service centers manufacture blocks cut from steel plates according to customers' requests. Products are cut by using flame cutting, plasma cutting and laser cutting methods. Case supply chain was measured during five years and two main customers with two main products were selected to make measurements. Profitability measurements were done two times to be sure about the results and to make comparisons between measurements.

\section{Order book analysis}

Customers of the case production plant in 2006-2009 are presented in the image below. In 2006 the production plant had 79 customers, whereas in 2008 it had 264 customers. The production plant serves corporate group's internal customers, whose proportion of the total production was significant each year. In 2009 volumes of internal customers increased and volumes of external customers decreased. Due to this, the number of customers in 2009 was 189. Compared to the volume of the production plant, the number of customers is very considerable. 


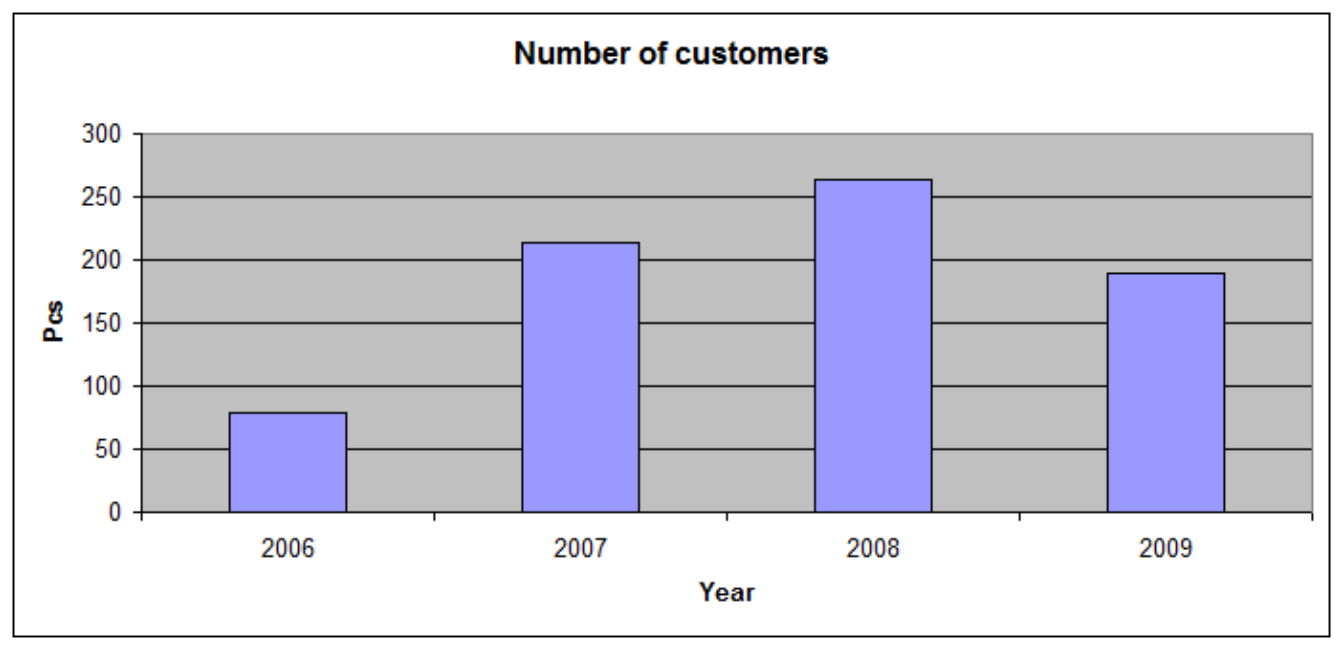

Figure 2: Number of customers 2006-2009

Manufacturing volumes per customer are divided among the 20 largest customers so that the first four customers form the largest portion of sales. These customers are internal customers. Volume of external customers is roughly the same with regards to all the 16 biggest customers. After this the volumes decrease to very small amounts. Considering the number of customers there are numerous low volume customers.

In 2005, 955 tons was manufactured. In 2006, increasing production as well as rationalization of the production facilities began. Furthermore, in 2006 a new operation control system was implemented in the production plant. In 2006, 8118 tons of steel parts were manufactured, which means a growth of almost nine times over the previous year. The following year, in 2007, production capacity of the production plant was mobilized more efficiently and benefits of the production control system could be utilized. The amount produced in 2007 was 15508 tons, which was nearly double 2006 production. In 2008 the amount produced increased to 24147 tons, which was 1,5 times that of year 2007. The period from 2005 to the end of 2008 was a time of rapid economic growth which was also seen in the growth of sales volumes. In 2009 sales faded as did the order books of customers. Regardless of this the production plant was able to manufacture 27070 tons of steel parts. As demand from external customers faded, the compensating fact proved to be the moving of workloads of the large consolidated company from another production plant to the case production plant which could function very efficiently. Especially significant is the fact that since 2005 the stock of machines has not changed much. The whole SC has been developed and growth has been wilfully forged. 


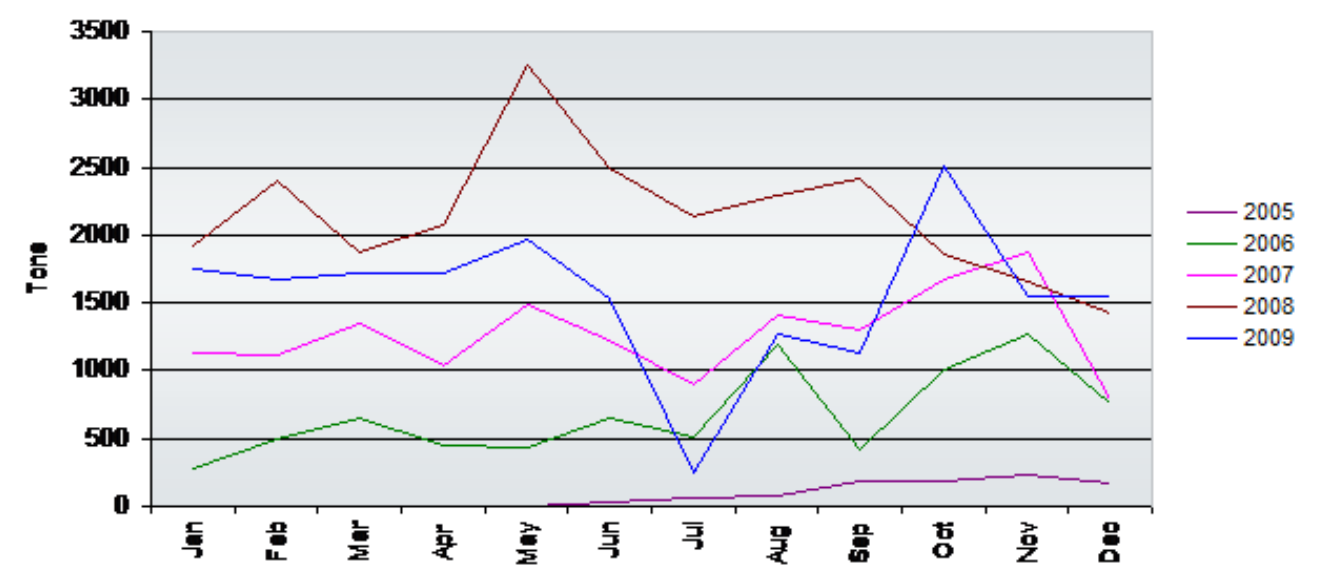

Figure 3: Output of the case production plant in 2005-2009

\section{Delivery reliability of the orders}

In 2005 delivery reliability averaged out 37.5 percent. In 2006 delivery reliability averaged out at 47.33 percent. There was a very significant improvement in delivery reliability in 2007 when it averaged out at 96.8 percent. After growth in production settled in 2008 and 2009, it has been possible to maintain delivery reliability at a good level. In 2008 delivery reliability was 96.5 percentand in 2009 almost 100 percent. Management of capacity has been made more efficient and co-operation of sales and production has been improved. All the challenges related to launching of production plant have been overcome as growth is steadying and the operations are stabilizing.

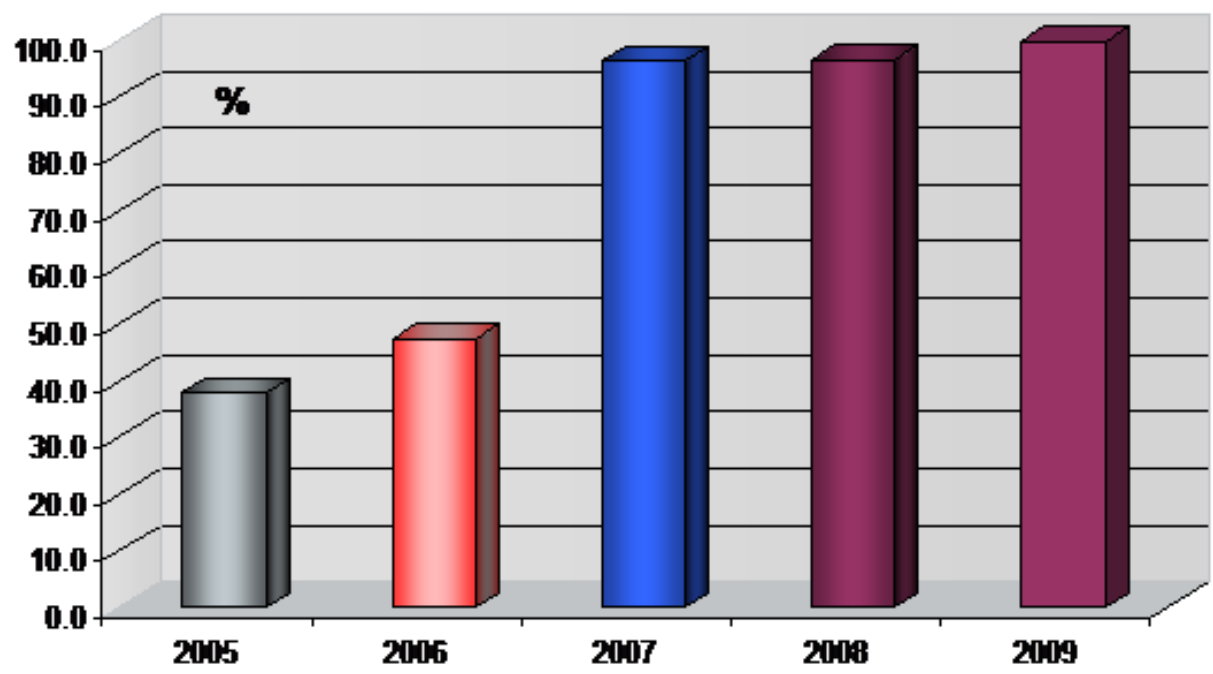

Figure 4: Delivery reliability per year in 2005-2009 


\section{Lead-time and profitable analysis in the first measurement}

\section{Product A profitability}

Profit margin of the order was $-45.9 \%$ and hence the order was unprofitable. Process time of the order was 134.1 hours. Total lead-time was 23 days and proportion of process time was determined to be 24.3 percent.

Table 2: Cost efficiency of Product A of Customer A

\begin{tabular}{llllll}
\hline Results & $\begin{array}{l}\text { Product } \\
\text { order }\end{array}$ & $\begin{array}{l}\text { / Profit margin of Total lead-time Process } \\
\text { the order }\end{array}$ & $\begin{array}{l}\text { time Proportion of } \\
\text { (days) }\end{array}$ & $\begin{array}{l}\text { (hrs) / order } \\
\text { process time \% }\end{array}$ \\
\hline Total & 8 & -45.9 & 23 & 134.08 & 24.3 \\
\hline
\end{tabular}

\section{Lead-time for product $A$}

Concerning products for Customer A, the problem has been long lead-times. 19 similar orders were manufactured during the period of time. Dispersion in period for the fulfilment for the orders was from nine to 43 days. Average for product lead-times was 27.7 days.

Delivery accuracy for orders of Customer A's Product A varied a great deal. At the beginning of the year all orders were overdue by as much as eight days. Delivery accuracy for the latest orders was 100 percent. Five of the orders were delivered 1-6 days earlier than the given time of delivery.

Production time a.k.a. process time of the order was 134.8 hours, which makes almost six days. Process time of one stage was 16.85 hours, and to produce the whole order, process time was spent from the period for the fulfilment of the order was 24.3 percent. Lead-time of the SC was 23 days.

Proportion of stages of work in production time was studied by counting up actual production times of all the stages of work in the orders and comparing them to the production time of the whole order. Cutting took 54.91 hours and was 42 percent of the production time. The most surprising discovery was the fact that deburring took 34.98 hours and made approximately 26 percent of the production time. Bevelling took 25.98 hours that equals 19 percent of production time. Picking up material, planning, collecting and blasting make up 13 percent of production time. 


\section{Product B profitability}

Production time spent in manufacturing the order was determined on the basis of reports as well as by clocking different stages of work. Some erroneous reporting was noticed in reporting of hours. Actual values for these erroneous values were defined. Picking up material, collecting and dispatch were measured during the production of the order. All the information regarding actual hours was put together in a table with the help of which profitability calculations were carried out. Final results were gathered in a summary table where the results were reviewed part- and order-specifically. The profit margin of Customer B's order reviewed was 7.76 percent. Process time of the order was 180.12 hours. Total leadtime was 28 days and proportion of process time in the total lead-time was 26.80 percent.

Table 3: Cost efficiency of Product B of Customer B

\begin{tabular}{|c|c|c|}
\hline Products & / Profit of the order Total & lead-time Process time (hrs) Proportion \\
\hline order & (days) & process time $\%$ \\
\hline 8 & 28.00 & 180.12 \\
\hline
\end{tabular}

\section{Product B lead-times}

During the period of time in question, the number of orders manufactured was 13. There was great deal of dispersion (from ten to 83 days) in time for fulfilment of an order. Average of periods for fulfilment of an order for Product B was 44.7 days. Proportion of process time in the whole period for fulfilment of an order was very small and there was a great deal of waiting time.

There are clearly challenges with regards to on-time delivery of products for Customer B. At the beginning of the year shipments were delivered as much as 25 days before the agreed date of delivery. None of the orders was 100 percent delivered on time. Towards the end of the period under review shipments were delivered as much as 35 days late.

The order from Customer B included parts for eight products. The production time a.k.a. process time of the order was 166.62 hours, which is approximately 26.80 percent of the period for fulfilment of an order. The period for fulfilment of an order for the order was 28 days. There were large buffer stocks between the stages of work. Production is controlled in a manner in which after one stage of work is completed, the material is transferred to the next stage of work. Due to this the proportion of process time in the period for fulfilment of an order is small. 
Percentages of work stages of production time was studied by adding up all the actual manufacturing times of each stage of work and comparing them to the production time of the order. Cutting took 36.14 hours, which is 23 percent of the production time for the whole order. Cutting takes most time from the production time. The proportion of edging in the production time was 37.05 hours, which is approximately 22 percent of the production time used in producing the order. Deburring took 33.81 hours and 20 percent of the total production time. The proportion of deburring in the production time is surprisingly large and due to the stage of work being very manual it results in high costs. Sand blasting took 25.44 hours, approximately 15 percent of the production time. Collecting took 23.92 hours, approximately 14 percent of the production time. The proportion of time spent in collection also for Customer B's product is very significant. It is a time-consuming stage of work. Customer B has provided very strict instructions on how the products are to be packed and dispatched to customer. It takes two employees and approximately three days in one shift to carry out this stage of work. The proportion of planning and materials management functions in the production time is approximately 6 percent.

\section{Lead-time and profitability analysis in the second measurement}

\section{Product A profitability}

Second measurements were done only for product A, because of product B production was finished during measurement period. A typical order that included parts for ten products was selected for review. Production time was studied using the same procedures as earlier. Times were obtained from the production control system and by measuring stages of work manually. The profit margin of the order was 19 percent, which is - unlike previous year - clearly profitable. Total lead-time was 34 days. Compared to the previous measurement, it increased 11 days. Process time was 115.3 hours per order, which shows clear improvement compared to the previous measurement. This is due to the fact that in the previous measurement there were 8 completed products for the order instead of the 10 products measured in this measurement. The proportion of process time was 14.1 percent. It decreased almost 13 percentage units due to the total lead-time increasing compared to the previous measurement. 
Table 4: Customer A, cost-efficiency of Product A

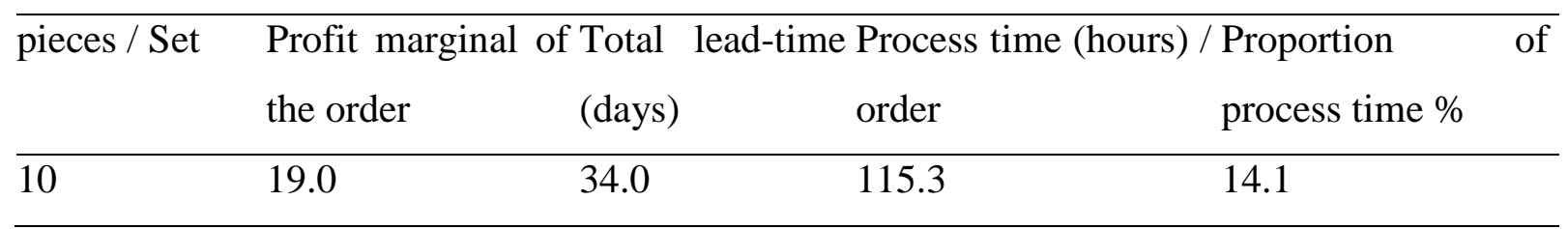

\section{Lead-time of product $A$}

During the second measurement, lead-times were studied by collecting the information for 2007 regarding the orders to be measured. During the measuring period, a total of 18 products were manufactured. Compared to the previous measurement, the number of measurement samples has increased by one order. In periods for the fulfilment of an order, dispersion had increased clearly from 12 days to 78 days, whereas it previously was from 9 days to 43 days. The average of periods for the fulfilment of an order for Product A was 46 days, which is nearly 19 days more than in the previous measurement.

Delivery accuracy was studied for the same orders. Dispersion of delivery accuracy is especially large, from zero days to as much as 24 days late. None of the orders was delivered before the requisite date of delivery. There has been a great improvement in delivery accuracy compared to the previous measurement. In the latter measurement, there were as many as five orders delivered on time and few orders that were only one day late. During the previous measurement, orders were delivered well beforehand or late. In the latter measurements it was perceived that dispersion of delivery accuracy has increased.

\section{Process time, Product A}

The order under review included ten pieces of Product A. Process time of the order was 115.29 hours. It took nearly 20 hours less time to manufacture the order than during the previous measurement. Furthermore, it is worth noting that the results of the first measurement covered productions of ten pieces and the latter productions of eight pieces. In completing the whole order, the proportion of process time in the whole period for the fulfilment of an order was 14.1 percent. Lead-time of the SC was 34 days.

The proportion of work stages in the production time was studied also in the latter measurements. Cutting took 45.10 hours, whereas a year earlier it took 54.91 hours. Cutting makes up 39 percent of the total production time and hence it decreased by four percentage units. Deburring took 32.10 hours, in which an improvement of two hours could be perceived. Bevelling took 16.20 hours, which showed improvement compared to the 25.98 hours in the previous measurements. Bevelling makes up 14 percent of the total production time. Picking 
up material, planning, collecting and blasting took seven percent of production time. Development of five percent has taken place.

\section{Managerial analysis of supply chain measurements}

SCM was measured at the case production plant during two different periods of time. The aim of two different measurement stages was to obtain information regarding usability of the selected indicators. It proved to be very challenging to carry out the measurements due to the operational environment being highly dynamic. Production volume, changes in the products manufactured as well as updates of the data system created challenges in performing the measurements. Corresponding measurements had not been carried out before, so the methods of measurement as well as the information obtained from the measurements had to be created from scratch. Use of the data systems could not be made in a most efficient manner because no corresponding reports have been created in the systems. The data obtained from the data systems had to be gathered from various sectors.

The results of the measurements reflect the efficiency of the SC of the case production plant very well. The most astonishing result is obtained from comparing the lead-time of the whole SC to production time a.k.a. process time. The proportion of process time in the whole period for the fulfilment of an order is approximately between 10-25 percent. The proportion of work stages in production time had also changed between the two different measurements. The proportion of manual work stages in production time had decreased and the proportion of automated work stages had remained more or less the same.

Comparison information regarding Product A in 2006 and 2007 is presented in the table. In 2006, one order included parts for the 8 products manufactured by the customer and in 2007 the order contained parts for 10 manufactured products. Profitability of the order has turned from loss to profit. Total lead-time has increased from 23 days to 34 days. Process time of order has decreased from 134 hours to 115 hours and hence the process time of plate parts for one product manufactured by the customer has decreased by approximately 30 percent. The proportion of process time has decreased from 24 percent to 14.1 percent, because the total lead-time of the orders under review has increased from 23 days to 34 days. 
Table 5: Comparisons of Product A in 2006 and 2007

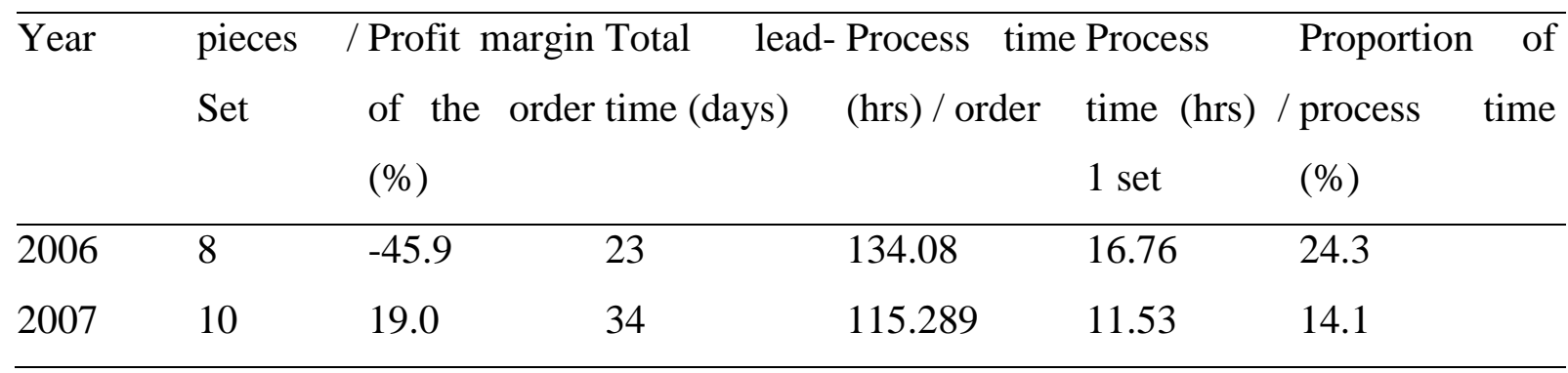

In the case production plant's SC process, typical problems presented in literature can be perceived. Load of production has been varying a great deal at the case production plant. Monthly variation is very large. This is due to a short order book and weak practices in customers' forecasting. There is also a great deal of variation in the loading of work stages. To enable stabilizing variations of capacity in production, employees should be more multiskilled. If there is no work at a given stage of work, an employee could be moved to a post where resources are needed. Loading could be steadied if the bottlenecks of bevelling and finishing would have enough machines and devices. One should pay close attention to these stages of work when loading production. Each hour lost in the backed up stages of work is directly comparable to profit of the company, because the amount of products completed depends on the amount of the products that have gone through the bottlenecks. Bottlenecks could be reduced by increasing machinery to the backed up stages of work and at times moving employees to deal with the backlogs in the bottlenecks.

\section{CONCLUSIONS}

The indicators consist of four different parts: order book analysis, outcome, time and managerial analysis. The SC was measured with the help of order book analysis. The volume of orders was analyzed and two customer cases were selected. Through these customer cases, cost-efficiency of the SC was measured. With the help of order book analysis it is possible to obtain an overview of the volume of orders, production volumes and delivery accuracy of the case production plant. It is easy to generalize as an indicator in various SCs. The indicator can be utilized regardless of the branch of industry or production plant in analyzing the SC of manufacturing production.

In measuring the SC, cost-efficiency is defined as the costs of the products to be manufactured on the basis of measured production times as well as machine hour rates. A cost-efficiency indicator was used to measure the costs allocated to the order of the whole SC of the largest customer of the case production plant during two different periods of time. The 
results obtained when measuring cost-efficiency were reliable and they could be utilized very well.

The SC was measured from the point of view of time during two different periods of time by measuring lead-times and production times of orders as well as the ratio of production times and lead-times. Also delivery accuracy measurements are related to time. Furthermore, delivery accuracy was reviewed from two different periods of time. Time lays a foundation also for measuring cost-efficiency, because the basis is measuring costs according to machine hour rates and time spent in different stages of work. According to recognized academic Goldratt (1992), the most essential indicator of the SC is lead-time (Goldratt, Cox 1992).

Managerial analysis is an analysis by persons involved in the SC or people monitoring the effectiveness of SCM from outside. In managerial analysis measurement the aim is to draw conclusions regarding the entire SC and avoid partial optimization. The analysis concentrated also on rationalizing capacity management of the production plant.

\section{Framework as a tool for practical supply chain measurements}

In the study, a performance measurement framework was created for the needs of manufacturing industry. This series of indicators is a tool for managers whose work is related to SC development. There has been a demand for indicators for the SC. The foundation of development is recognizing the present state. According to it, goals to required development must be set. The usability of the tool was tested in the measurements in practice. The indicators proved to be very usable for measuring the case SC and the framework could be used for measuring various SCs in manufacturing industry. The tool can be applied to various SCs but it has to be tailored by considering any special features of a chain.

Indicators for SC performance measurement were tested in practice at a typical company that manufactures prefabricated products. This very much narrows the chasm between theory and practice. The measurements in practice were conducted by the researcher and managers involved in the SC. The set of indicators established on the basis of theoretical frame of reference was transformed to a practical tool. According to interviews as well as the feedback received, the indicators serve managers at the practical level extremely well when they are managing and developing the SC. 


\section{REFERENCES}

Aitken, J., Childerhouse, P., Christopher, M. and Towill, D. 2005, "Designing and Managing Multiple Pipelines", Journal of Business Logistics, vol. 26, no. 2, pp. 73.

Balsmeier, P.W. and Voisin, W.J. 1996, "Supply chain management: A time-based strategy", Industrial Management, vol. 38, no. 5, pp. 24-27.

Beamon, B.M. 1999, "Measuring supply chain performance", International Journal of Operations and Production Management, vol. 19, no. 3, pp. 275-292.

Ben Naylor, J., Naim, M.M. and Berry, D. 1999, "Leagility: Integrating the lean and agile manufacturing paradigms in the total supply chain", International Journal of Production Economics, vol. 62, no. 1-2, pp. 107-118.

Bhagwat, R. and Sharma, M.K. 2007, "Performance measurement of supply chain management: A balanced scorecard approach", Computers and Industrial Engineering, vol. 53, no. 1 , pp. 43-62.

Bigliardi, B. and Bottani, E. 2010, "Performance measurement in the food supply chain: A balanced scorecard approach", Facilities, vol. 28, no. 5-6, pp. 249-260.

Brewer, P.C. and Speh, T.W. 2001, "Adapting the balanced scorecard to supply chain management", Supply Chain Management Review, vol. 5, no. 2, pp. 48-56.

Brewer, P.C. and Speh, T.W. 2000, "Using the balanced scorecard to measure supply chain performance", Journal of Business Logistics, vol. 21, no. 1, pp. 75-93.

Chan, F.T.S. 2003a, "Performance Measurement in a Supply Chain", International Journal of Advanced Manufacturing Technology, vol. 21, no. 7, pp. 534-548.

Chan, F.T.S. 2003b, "Performance measurement in a supply chain", International Journal of Advanced Manufacturing Technology, vol. 21, no. 7, pp. 534-548.

Chan, F.T.S. and Qi, H.J. 2003a, "An innovative performance measurement method for supply chain management", Supply Chain Management, vol. 8, no. 3, pp. 209-223.

Chan, F.T.S. and Qi, H.J. 2003b, "An innovative performance measurement method for supply chain management", Supply Chain Management: An International Journal, vol. 8, no. 3, pp. 209-223.

Chia, A., Goh, M. and Hum, S.-. 2009, "Performance measurement in supply chain entities: Balanced scorecard perspective", Benchmarking, vol. 16, no. 5, pp. 605-620.

Christopher, M. 1998, Logistics and supply chain management : strategies for reducing cost and improving service, 2.th edn, Financial Times; Pitman, cop, London. 
Cooper, M.C., Lambert, D.M. and Pagh, J.D. 1997, "Supply chain management: More than a new name for logistics", The International Journal of Logistics Management, vol. 8, no. 1, pp. 1-13.

Dasgupta, T. 2003, "Using the six-sigma metric to measure and improve the performance of a supply chain", Total Quality Management and Business Excellence, vol. 14, no. 3, pp. 355-366.

De Toni, A. and Tonchia, S. 2001, "Performance measurement systems Models, characteristics and measures", International Journal of Operations and Production Management, vol. 21, no. 1-2, pp. 46-70.

Dixon, J.R. 1990, "The new performance Challenge: Measuring operations for word-class competition", Business One Irwin, .

Dror, S. 2008, "The Balanced Scorecard versus quality award models as strategic frameworks", Total Quality Management and Business Excellence, vol. 19, no. 6, pp. 583-593.

Epstein, M. and Manzoni, J.-. 1998, "Implementing corporate strategy: From tableaux de bord to balanced scorecards", European Management Journal, vol. 16, no. 2, pp. 190-203.

Fynes, B., Voss, C. and De Búrca, S. 2005, "The impact of supply chain relationship dynamics on manufacturing performance", International Journal of Operations and Production Management, vol. 25, no. 1, pp. 6-19.

Goldratt, E.M. and Cox, J. 1992, The goal : a process of ongoing improvement, 2. rev. ed. edn, North River Press, Great Barrington (Mass.).

Gunasekaran, A., Patel, C. and McGaughey, R.E. 2004, "A framework for supply chain performance measurement", International Journal of Production Economics, vol. 87, no. 3, pp. 333-347.

Gunasekaran, A., Patel, C. and Tirtiroglu, E. 2001, "Performance measures and metrics in a supply chain environment", International Journal of Operations and Production Management, vol. 21, no. 1/2, pp. 71-87.

Gunasekaran, A., Williams, H.J. and McGaughey, R.E. 2005, "Performance measurement and costing system in new enterprise", Technovation, vol. 25, no. 5, pp. 523-533.

Hieber, R. 2002, Supply Chain Management: A Collaborative Performance Measurement Approach, .

Hoek, R.I.v. 1998, "“Measuring the unmeasurable" - measuring and improving performance in the supply chain", Supply Chain Management: An International Journal, vol. 3, no. 4, pp. 187-192. 
Holmberg, S. 2000, "A systems perspective on supply chain measurements", International Journal of Physical Distribution and Logistics Management, vol. 30, no. 10, pp. 847868.

Kaplan, R. 1993, "Putting the balanced scorecard to work", Harvard business review, vol. 71, no. 5 , pp. 134-144.

Kaplan, R.S. and Norton, D.P. 2001, "Transforming the balanced scorecard from performance measurement to strategic management: Part I", Accounting Horizons, vol. 15, no. 1, pp. 87-104.

Kaplan, R.S. and Norton, D.P. 1996, "Linking the balanced scorecard to strategy", California management review, , no. 1, pp. 53-79.

Kaplan, R.S. and Norton, D.P. 1992, "The balanced scorecard--measures that drive performance.", Harvard business review, vol. 70, no. 1, pp. 71-79.

Kaplan, R.S. 1996, "Using the balanced scorecard as a strategic management system.", Harvard business review, vol. 74, no. 1, pp. 75-85.

Keegan, D.P., Eiler, R.G. and Jones, C.R. 1989, "Are your performance measures obsolete?", Management Accounting, , no. 12, pp. 45-50.

Kessler, E.H. and Chakrabarti, A.K. 1996, "Innovation speed: A conceptual model of context, antecedents, and outcomes", Academy of Management Review, vol. 21, no. 4, pp. 1143 1191.

Lambert, D.M., Cooper, M.C. and Pagh, J.D. 1998, "Supply chain management: Implementation issues and research opportunities", The International Journal of Logistics Management, vol. 9, no. 2, pp. 1-19.

Lawrie, G. and Cobbold, I. 2004, "Third-generation balanced scorecard: Evolution of an effective strategic control tool", International Journal of Productivity and Performance Management, vol. 53, no. 7, pp. 611-23.

Li, S., Rao, S.S., Ragu-Nathan, T.S. and Ragu-Nathan, B. 2005, "Development and validation of a measurement instrument for studying supply chain management practices", Journal of Operations Management, vol. 23, no. 6, pp. 618-641.

Li, Z., Xu, X. and Kumar, A. 2007, "Supply chain performance evaluation from structural and operational levels", , pp. 1131.

Lin, L.-. and Li, T.-. 2010, "An integrated framework for supply chain performance measurement using six-sigma metrics", Software Quality Journal, vol. 18, no. 3, pp. $387-406$. 
Lockamy III, A. and McCormack, K. 2004, "Linking SCOR planning practices to supply chain performance: An exploratory study", International Journal of Operations and Production Management, vol. 24, no. 12, pp. 1192-1218.

Mehrjerdi, Y.Z. 2009, "Excellent supply chain management", Assembly Automation, vol. 29, no. 1 , pp. 52-60.

Morgan, C. 2004, "Structure, speed and salience: performance measurement in the supply chain", Business Process Management Journal, vol. 10, no. 5, pp. 522-536.

Neely, A., Mills, J., Platts, K., Richards, H., Gregory, M., Bourne, M. and Kennerley, M. 2000, "Performance measurement system design: Developing and testing a processbased approach", International Journal of Operations and Production Management, vol. 20, no. 10 , pp. 1119-1145.

Ramaa, A., Rangaswamy, T.M. and Subramanya, K.N. 2009, "A review of literature on performance measurement of supply chain network", 2009 2nd International Conference on Emerging Trends in Engineering and Technology, ICETET 2009, 16 December 2009 through 18 December 2009, pp. 802.

Ren, T. 2008, "Application of supply chain performance measurement based on SCOR model", 2008 International Conference on Wireless Communications, Networking and Mobile Computing, WiCOM 2008, 12 October 2008 through 14 October 2008.

Shepherd, C. and Gunter, H. 2006, "Measuring supply chain performance: current research and future directions", International Journal of Productivity and Performance Management, vol. 55, no. 3/4, pp. 242-258.

Simchi-levi, D., Kaminsky, P. and Simchi-levi, E. 2004, "'Managing the supply chain - The definitive guide for the business professional'", New York, , pp. 116-118.

Sink, D.S. and Tuttle, T.C. 1989, Planning and Measurement in Your Organization of the Future, .

Stalk, G. 1988, "Time - The next source of competitive advantage", Harvard business review, vol. 66, no. 4, pp. 41-51.

Stank, T.P., Keller, S.B. and Daugherty, P.J. 2001, "Supply chain collaboration and logistical service performance", Journal of Business Logistics, vol. 22, no. 1, pp. 29-48.

Stephens, S. 2001, "Supply Chain Operations Reference Model Version 5.0: A New Tool to Improve Supply Chain Efficiency and Achieve Best Practice", Information Systems Frontiers, vol. 3, no. 4, pp. 471-476.

Supply Chain Council 2005, . 
Suwignjo, P., Bititci, U.S. and Carrie, A.S. 2000, "Quantitative Models for Performance Measurement System", International Journal of Production Economics, vol. 64, no. 1, pp. 231-241.

Tangen, S. 2004, "Performance measurement: From philosophy to practice", International Journal of Productivity and Performance Management, vol. 53, no. 8, pp. 726-737.

Thakkar, J., Deshmukh, S.G., Gupta, A.D. and Shankar, R. 2007, "Development of a balanced scorecard: An integrated approach of Interpretive Structural Modeling (ISM) and Analytic Network Process (ANP)", International Journal of Productivity and Performance Management, vol. 56, no. 1, pp. 25-59.

Toni, A.D. and Tonchia, S. 2001, "Performance measurement systems - Models, characteristics and measures", International Journal of Operations \& Production Management, vol. 21, no. 1/2, pp. 46-71.

Van Hoek, R.I. 2001, "The contribution of performance measurement to the expansion of third party logistics alliances in the supply chain", International Journal of Operations and Production Management, vol. 21, no. 1-2, pp. 15-29.

Vesey, J.T. 1992, "Time-to-market: Put speed in product development", Industrial Marketing Management, vol. 21, no. 2, pp. 151-158.

Wang, F.-., Du, T.C. and Li, E.Y. 2004, "Applying Six-Sigma to supplier development", Total Quality Management and Business Excellence, vol. 15, no. 9-10, pp. 1217-1229.

$\mathrm{Xu}$, J. 2008, "A six sigma-based methodology for performance measurement of a supply chain", 2008 International Conference on Wireless Communications, Networking and Mobile Computing, WiCOM 2008, 12 October 2008 through 14 October 2008.

Xu, X. and Li, C. 2008, "The supply chain performance evaluations indicator system based on benchmark balanced scorecard", . 